\title{
SOFC modelling considering radiation heat transfer
}

\author{
Wael Alimi ${ }^{1,2, *}$, Ridha Chouikh ${ }^{2}$, and Amen Allah Guizani ${ }^{1}$ \\ ${ }^{1}$ Laboratory of Thermal Processes, Research and Technology Center of Energy, Borj-Cedria, BP95 Hammam-Lif 2050, Tunisia \\ ${ }^{2}$ Physics Department, Faculty of Science, King Khalid University, PO Box 9004, Abha 61413, Saudi Arabia
}

Received: 29 October 2019 / Accepted: 9 February 2020

\begin{abstract}
In this study, the influence of radiation heat transfer within a planar SOFC is investigated. The numerical model is made by performing two-dimension mathematical model describing mass, momentum and heat transport phenomena coupled with electrochemical reactions. The finite volume method is used to solve the governing equations. Compared with literature results, the simulations show that radiation reduces temperature gradients and has a significant effect on enhancing heat transfer within the SOFC and counter balancing thermal dissipation induced by activation, concentration and ohmic polarisations. Thus, it must be included for an accurate model.
\end{abstract}

Keywords: Planar SOFC / overpotential / radiation / finite volume method

\section{Introduction}

Nowadays Solid Oxide Fuel Cells (SOFC) are the subject of growing interest because of their higher actual and potential performances in terms of heat and electric power. In fact, the hot temperatures of rejected gas, about $800^{\circ} \mathrm{C}$ allow an interesting valorization by adding a cogeneration combined cycle to the SOFC unit. The SOFC has an electric efficiency around $50 \%$ and when coupled to a gas turbine with an alternator, the efficiency can reach $70 \%$ with input pressurized gas. It is also possible to use the exhausted gas calories in order to cogenerate steam and electricity so the global efficiency in terms of heat and electricity can be superior to $80 \%$. The high operating temperature range from $800^{\circ} \mathrm{C}$ to approximately $1000^{\circ} \mathrm{C}$ permitting an internal reforming of the fuel (for example methane) under the action of the water steam inside the SOFC. The efficiency of this operation is much higher than in case of external reforming for a Proton Exchange Membrane Fuel Cell (PEMFC). Actually, there are two main technologies for SOFC, tubular and planar geometries. The manufacturer Westinghouse develops the first one, which is in form of tubes pilled together. The ionic current $\left(\mathrm{O}_{2}^{-}\right)$passes from inside the tube where the air flows to outside where fuel, Hydrogen or methane is circulating. The planar technology, developed by manufacturer such as Siemens and Sulzer, is relatively recent. It is composed of sandwich of ceramic layers (anode,

\footnotetext{
* e-mail: alimi_wael@yahoo.com
}

electrolyte and cathode) with interconnector separating fuel and oxidant and offers better performance compared to tubular technology. A Nickel/Zirconia (Ni-YSZ) anode, doped Lanthanum Strontium Ferrite (LSF) or doped Lanthanum Strontium Manganite (LSM) cathode, and Yttria Stabilized Zirconia (YSZ) electrolyte compose a typical planar SOFC. The performance of SOFC depends on heat, mass and charge transport occurring simultaneously inside it and on electrochemical and fluids processes, which affect strongly its efficiency and power. These phenomena need to be explored and clarified by means of experiments or physical and mathematical modelling. Heat transfer occurs in form of conduction in solid parts, convection in flow channels and porous electrodes and radiation in both solid and porous media. Since SOFC operates at high temperature, the radiation heat cannot be neglected and needs to be investigated when modelling thermal process. Many studies took in consideration radiation transfer in their models. They are varied from extremely simplified to comprehensive and complex numerical calculations solved often with commercial CFD and the results are sometimes confusing or conflicting, due to the lack in experimental data for radiative proprieties of electrodes and electrolyte. Hartvigsen et al. [1] are the first researcher who included radiation term to their model and conclude that it has a significant influence on the results. Murthy et al. [2] used Schuster-Schwarzschild method to model radiation transfer in electrolyte, considered as an optically thin body and they used Rosseland diffusion approximation for electrodes considered as an optically thick body to prove the importance of radiation heat 


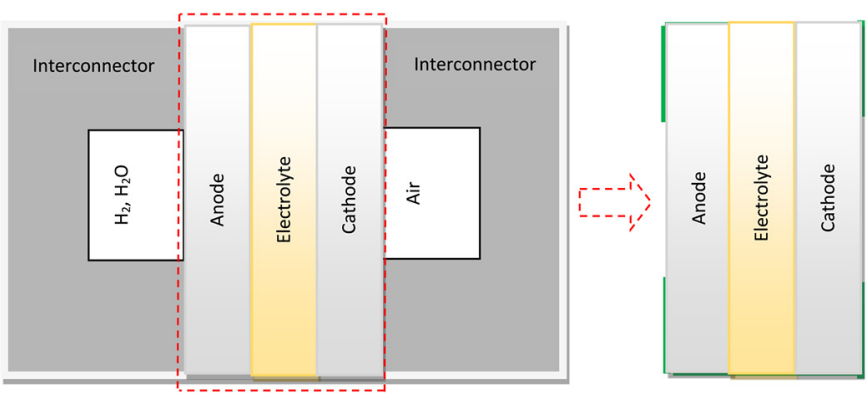

Fig. 1. Schematic representation of the studied SOFC.

transfer. The mathematical model of Damn et al. [3,4] showed that radiation can be excluded in the electrodes but not in electrolyte, and they found that its overall impact on temperature field in SOFC is relatively small. Daun et al. [5] compared results obtained by pure conduction model and combined conduction-radiation calculation and concluded that the difference between them is relatively small.

Several SOFC modelling studies appeared last years, trying to investigate radiation heat effect such as the works of Grzegorz Brus et al. [6], Kee et al. [7], Bao et al. [8], Imen Majeri et al. [9], García-Camprubí et al. [10] and Ferrero et al. [11]. However, all the existing models considered only ohmic heat by joule effect, neglecting radiation heat in the energy equation and didn't take into account other possible heat sources caused by concentration and activation overpotentials and chemical reaction such as the work of Ismet Tikiz et al. [12] and van Biert et al. [13]. However, this is not a reasonable simplification due to the complex properties of the SOFC materials.

The aim of the present study is to investigate the radiation heat influence in a typical planar SOFC by including all possible heat sources that occur inside it. This is done by developing a comprehensive numerical model in the different layers with various geometries in order to validate these assumptions often simplifying computational task.

\section{Modeling approach}

The studied physical model is shown in Figure 1, it is a planar SOC fed with Hydrogen as a fuel and Oxygen as oxidant. The electrochemical equations at the anode, cathode and the overall equation are respectively:

$$
\begin{gathered}
\mathrm{H}_{2}+\mathrm{O}^{2-} \rightarrow \mathrm{H}_{2} \mathrm{O}+2 \mathrm{e}^{-} \quad \text { (Anode) } \\
1 / 2 \mathrm{O}_{2}+2 \mathrm{e}^{-} \rightarrow \mathrm{O}^{2-} \quad \text { (Cathode) } \\
\mathrm{H}_{2}+1 / 2 \mathrm{O}_{2} \rightarrow \mathrm{H}_{2} \mathrm{O} \quad \text { (Global reaction) }
\end{gathered}
$$

\subsection{Governing equations}

Heat, mass and charge transfer as well as electrochemical reactions occur simultaneously within the SOFC and are strongly coupled. Thus, these phenomena affect the global performance of the cell and needed to be investigated. The next sections are dealing with their mathematical modeling.

\subsubsection{Mass conservation}

The species balance equation is:

$$
\begin{aligned}
\frac{\partial}{\partial x} & \left(\varepsilon \rho u \cdot X_{i}\right)+\frac{\partial}{\partial y}\left(\varepsilon \rho v \cdot X_{i}\right) \\
& =\frac{\partial}{\partial x}\left(\rho D_{e f f} \cdot \frac{\partial X_{i}}{\partial x}\right)+\frac{\partial}{\partial y}\left(\rho D_{e f f} \cdot \frac{\partial X_{i}}{\partial y}\right)+S_{X_{i}}
\end{aligned}
$$

$X_{i}$ is the species mass fraction $\left(i=\mathrm{O}_{2}, \mathrm{H}_{2}, \mathrm{H}_{2} \mathrm{O}\right), \varepsilon$ is the porosity, $D_{\text {eff }}$ is the effective diffusion coefficient in porous electrodes defined by $D_{\text {eff }}=\frac{\varepsilon}{\tau} D, \rho$ is the mass density and $(u, v)$ are velocity components. The source term $S_{X i}$ is related to the electrochemical reactions taking place in the electrolyte/electrode interface and it is written as follows:

$$
\begin{gathered}
S_{\mathrm{H}_{2}}=-\frac{M_{\mathrm{H}_{2}}}{2 F} I, \quad S_{\mathrm{H}_{2} \mathrm{O}}=\frac{M_{\mathrm{H}_{2} \mathrm{O}}}{2 F} I \quad \text { (Anode) } \\
S_{\mathrm{O}_{2}}=-\frac{M_{\mathrm{O}_{2}}}{2 F} I \quad \text { (Cathode) }
\end{gathered}
$$

with $I$ is the current density.

\subsubsection{Momentum conservation}

The gas flow throughout the porous electrodes is described by the Darcy's law:

$$
\mathrm{u}=-\frac{\kappa}{\varepsilon \cdot \mu} \nabla P
$$

$P$ is the pressure, $\kappa$ is the permeability and $\mu$ is the viscosity. This equation is coupled with the continuity equation:

$$
\frac{\partial}{\partial x}(\varepsilon \rho u)+\frac{\partial}{\partial y}(\varepsilon \rho v)=0 .
$$

\subsubsection{Energy conservation}

The energy balance law can be written as follows:

$$
\begin{aligned}
& \frac{\partial}{\partial x}(\varepsilon \rho u e)+\frac{\partial}{\partial y}(\varepsilon \rho v e) \\
& \quad=\frac{\partial}{\partial x}\left(\lambda_{e f f} \frac{\partial T}{\partial x}\right)+\frac{\partial}{\partial y}\left(\lambda_{e f f} \frac{\partial T}{\partial y}\right)+S_{T}
\end{aligned}
$$

$e$ is the gas internal energy, $\lambda_{\text {eff }}$ is the effective conductivity determined by: $\lambda_{\text {eff }}=\varepsilon \lambda_{g}+(1-\varepsilon) \lambda_{s}, T$ is the temperature and $S_{T}$ is the heat source. $S_{T}$ is the sum of all generated/ dissipated heat:

$$
S_{T}=S_{a c t}+S_{\text {con }}+S_{\text {joule }}+S_{\text {rad }}+S_{\text {chem }}
$$


$-S_{\text {joule }}$ is the Joule effect heat due to electronic resistance in the electrodes and ionic resistance in the solid electrolyte and it is calculated as follows:

$$
S_{\text {joule }}=\frac{\eta_{\text {ohm }, k}}{\delta} I \text { with } \eta_{o h m, k}=\frac{e_{k}}{\sigma_{k}} I
$$

$\eta_{\text {ohm }}$ presents the Ohmic polarisation or overpotential, $e_{k}$ is the thickness and $\sigma_{k}$ is the electrical conductivity given by Yixiang et al [14]:

$$
\sigma_{k}=\left\{\begin{array}{l}
\frac{9.5 \times 10^{7}}{T} \exp \left(-\frac{1150}{T}\right) ; \text { anode } \\
\frac{4.2 \times 10^{7}}{T} \exp \left(-\frac{1300}{T}\right) ; \text { cathode } \\
3.34 \times 10^{4} \exp \left(-\frac{1300}{T}\right) ; \text { electrolyte }
\end{array}\right.
$$

$\delta$ presents the thickness of the region where heat is dissipated.

- $S_{a c t}$ is the heat due to activation overpotential in the electrodes calculated by:

$$
\begin{aligned}
S_{a c t, k} & =\frac{\eta_{a c t, k}}{\delta} I \quad \text { Where } \eta_{a c t, k} \\
& =\frac{R T}{F} \sinh ^{-1}\left(\frac{I}{2 i_{o, k}}\right)[15]
\end{aligned}
$$

$\eta_{a c t, k}$ is the activation overpotential and $i_{0, k}$ is the exchange current density defined by:

$$
\begin{aligned}
& i_{0, a n}=\gamma_{a}\left(\frac{P_{H_{2}}}{P_{0}}\right)\left(\frac{P_{H_{2} O}}{P_{0}}\right) \exp \left(-\frac{E_{a c t, a n}}{R T}\right) \\
& i_{0, c a}=\gamma_{c}\left(\frac{P_{O_{2}}}{P_{0}}\right)^{0.25} \exp \left(-\frac{E_{a c t, c a}}{R T}\right)
\end{aligned}
$$

$\gamma_{k}$ is a factor depending on the reaction, $E_{a c t}$ is the activation energy, $F$ stands for the Faraday number, $P_{0}$ is the gas pressure at the electrode/electrolyte interface and $R$ is the perfect gas constant.

$-S_{c o n}$ is the heat due to the concentration overpotentials in the electrodes expressed by:

$$
S_{c o n, k}=\frac{\eta_{c o n, k}}{\delta} I
$$

with [16]:

$$
\begin{gathered}
\eta_{c o n, a n}=\frac{R T}{2 F} \ln \left(\frac{P_{\mathrm{H}_{2} \mathrm{O}}^{I} \cdot P_{\mathrm{H}_{2}}^{f}}{P_{\mathrm{H}_{2} \mathrm{O}}^{f} \cdot P_{\mathrm{H}_{2}}^{I}}\right) \\
\text { and } \eta_{\text {con }, c a}=\frac{R T}{4 F} \ln \left(\frac{P_{\mathrm{O}_{2}}^{a}}{P_{\mathrm{O}_{2}}^{I}}\right)
\end{gathered}
$$

presenting the concentration overpotentials in the cathode or anode assuming that the electrochemical reactions occur only at the electrode/electrolyte interface. $P^{I}$ is the gas partial pressure at the electrode/electrolyte interface, calculated for each species as follows:

$$
\begin{aligned}
& P_{\mathrm{H}_{2}}^{I}=P_{\mathrm{H}_{2}}^{f}-\frac{R T e_{\text {anode }}}{2 F D_{\text {eff,anode }}} I \\
& P_{\mathrm{H}_{2} \mathrm{O}}^{I}=P_{\mathrm{H}_{2} \mathrm{O}}^{f}+\frac{R T e_{\text {anode }}}{2 F D_{\text {eff,anode }}} I \\
& P_{\mathrm{O}_{2}}^{I}=P-\left(P-P_{\mathrm{O}_{2}}^{f}\right) \exp \left(\frac{R T e_{\text {cathode }}}{4 F P D_{\text {eff,cathode }}} I\right)
\end{aligned}
$$

$-S_{\text {chem }}$ is the heat generated by the chemical reaction at the interface of anode/electrolyte; and can be expressed in term of enthalpy [17]:

$$
\begin{gathered}
Q_{\text {chem }}=-\Delta H_{f, H_{2} O}-2 F V, \\
\Delta H_{f, H_{2} O}=-(240506+7.3835 T)
\end{gathered}
$$

is the enthalpy formation of water and:

$$
V=E_{\text {ideal }}-\left(\eta_{\text {ohm }}+\eta_{\text {act }}+\eta_{\text {con }}\right)
$$

being the cell tension. $E_{\text {ideal }}$ is the ideal potential calculated by:

$$
E_{\text {ideal }}(T)=E^{0}(T)-\frac{R T}{2 F} \ln \left(\frac{X_{\mathrm{H}_{2} \mathrm{O}}}{X_{\mathrm{H}_{2}} X_{\mathrm{O}_{2}}^{1 / 2}}\right)
$$

and

$$
E^{0}(T)=1.2723-2.764510^{-4} T
$$

Therefore the expression of the chemical heat source is:

$$
S_{\text {chem }}=\frac{Q_{\text {chem }}}{2 F \delta} I .
$$

The electrodes are supposed as an optically Thick body $\left(\tau_{L=\beta L}>>1\right.$. The radiative heat flux is estimated through Rosseland approximation:

$$
q_{r a d}=-k_{r} . \nabla T
$$

where $k_{r}$ is the radiative conductivity defined as [3-5]:

$$
k_{r}=\frac{16 n^{2} \sigma T^{3}}{3 \beta_{r}}
$$

$\beta_{r}$ refers to the Rosseland-mean extinction coefficient, $\sigma$ is the Stefan-Boltzmann constant, and $n$ is the refractive index. The electrolyte is supposed gray non-scattering medium and optically thin $\left(\tau_{L=\beta L} \ll 1\right)$. Thus we can use the two-flux model proposed by Schuster-Schwarzschild to evaluate the radiative heat as $[3-5]$ :

$$
q_{r a d}=A e^{2 k x}+B e^{-2 k x}
$$




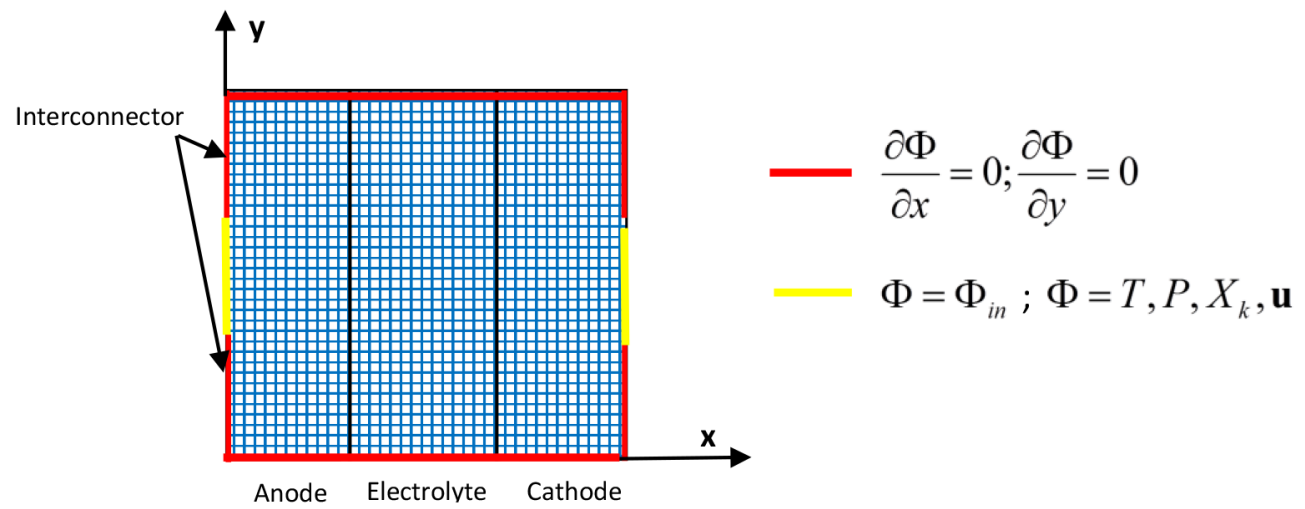

Fig. 2. Computation domain and boundaries conditions.

$A, B$ are given by:

$$
\begin{aligned}
& A=-\sigma\left(T_{\text {top }}^{4}-T^{4}\right) e^{-2 k L} \\
& B=\sigma\left(T_{b o t}^{4}-T^{4}\right)
\end{aligned}
$$

$T_{\text {top }}$ and $T_{b o t}$ are the two temperatures of the two isothermal sides of the medium separated by a distance $L$. The radiative source is obtained from the radiative heat flux by:

$$
S_{\text {rad }}=-\nabla \cdot q_{r a d}
$$

\subsection{Model implementation}

The considered governing equations are solved numerically by using the finite volume method, which consists of dividing the computational domain as shown in Figure 2, into a number of control volumes, each one surrounding a grid point and then integrating the differential equations over each control volume in order to obtain the discretised equations. The numerical code is written in a selfprogramming FORTRAN language. The numerical resolution is carried out with a SOFC properties and operating conditions summarized in Table 1.

The numerical simulations are validated with experimental results of Zhao et al. [18] and the currentvoltage curve was generated by the model for different values of operating temperatures (temperatures at channels flow entries) as shown in Figure 3. The simulated results have similar shape compared to the experimental data and become mush closer at higher temperatures. At higher currents, the concentration overpotentials become important and produce a voltage drop in the cell which results to the tailing effect observed in the curve at temperature $1073 \mathrm{~K}$.

\section{Results and discussion}

\subsection{SOFC performances}

The cell voltage and power density versus current density simulated by the model for the input parameters are

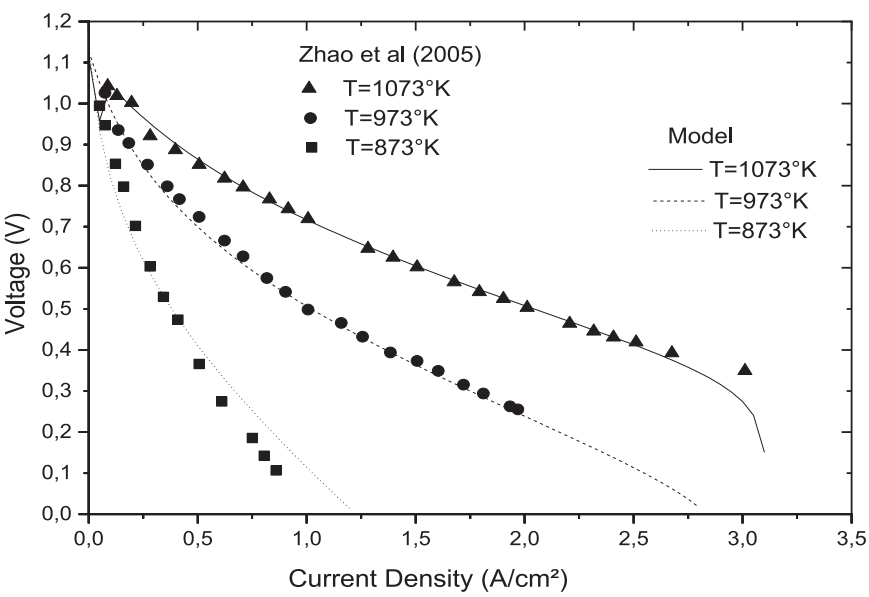

Fig. 3. Comparison between simulated and experimental cell voltages.

presented in Figure 4. The curves are plotted for various operating temperatures (at flow channels entries): $1000 \mathrm{~K}$, $1100 \mathrm{~K}, 1200 \mathrm{~K}$, and $1300 \mathrm{~K}$ and for three types of geometry of a planar SOFC namely: anode supported, electrolyte supported and cathode supported cell. The corresponding dimensions are set in Table 2 .

At temperature $1000 \mathrm{~K}$, the electrolyte supported SOFC shows the worst performance in terms of cell voltage and power density because of the high ohmic polarisation. However as the temperature increases, the power density in the cathode supported SOFC decreases until becoming small in comparison to the power density in the electrolyte supported geometry at temperature $1200 \mathrm{~K}$ $\left(0.45 \mathrm{~W} / \mathrm{cm}^{2}\right.$ to $\left.0.49 \mathrm{~W} / \mathrm{cm}^{2}\right)$. This is can be explained by the fact of growth of its cathodic concentration polarisation precisely which depends essentially on the oxygen diffusion process that becomes slower, due firstly to the used thick cathode and secondly to the poor effective oxygen gas diffusion coefficient which diminishes with increasing current density.

It should be noted that the cell voltage in case of cathode supported drop to zero when the current density reach approximately $0.5 \mathrm{~A} / \mathrm{cm}^{2}$ for all the range of temperatures. At this point, the cell attain its limits, but 
Table 1. SOFC properties and operating conditions $[5,16,17,19]$.

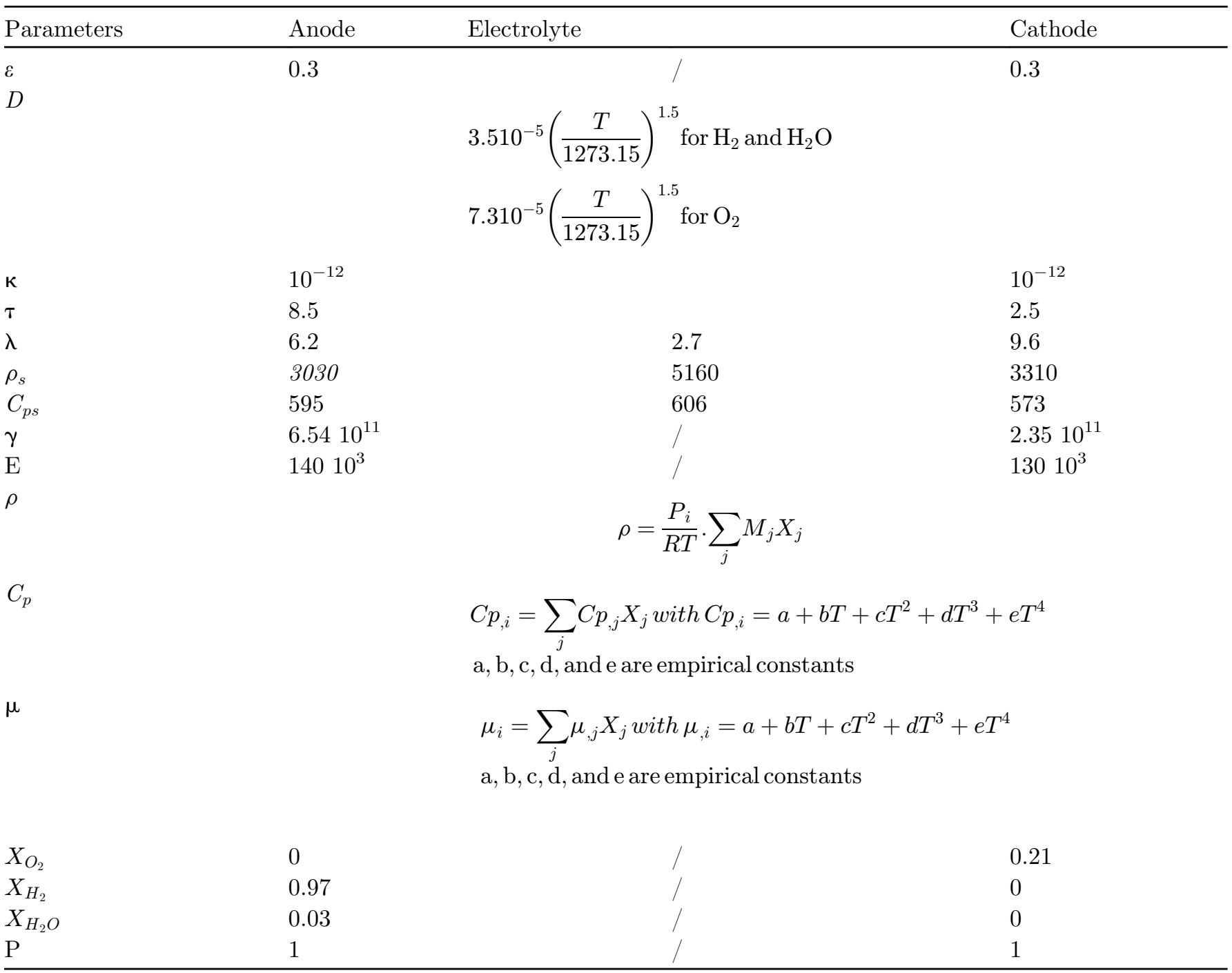

the values of cell voltage remain higher than in case of electrolyte supported, $0.95 \mathrm{~V}$ for first case to $0.9 \mathrm{~V}$ for last one at $1300^{\circ} \mathrm{K}$. The anode supported SOFC shows the best performance among the two other geometries. Its maximum power density increases from $0.32 \mathrm{~W} / \mathrm{cm}^{2}$ at $1000 \mathrm{~K}$ to $1.22 \mathrm{~W} / \mathrm{cm}^{2}$ at $1300 \mathrm{~K}$ with a current density equal to 0.7 $\mathrm{A} / \mathrm{cm}^{2}$ and $1.5 \mathrm{~A} / \mathrm{cm}^{2}$ respectively. The cell voltage exhibits a tail effect as the temperature increases due to the important concentration polarization which plays a crucial role at higher current densities.

According to Figure 5 (case of anode supported SOFC) for a temperature of $1000 \mathrm{~K}$, the cell voltage decreases from its Nernst Potential value to $0.035 \mathrm{~V}$ which corresponds to a current density equal to $1.3 \mathrm{~A} / \mathrm{cm}^{2}$. The power density increases to reach a pick value equal to $0.324 \mathrm{~W} / \mathrm{cm}^{2}$ when the current density is equal to $0.65 \mathrm{~A} / \mathrm{cm}^{2}$ and the cell voltage is equal to $0.5 \mathrm{~V}$. In this condition, the major tension loss is due to both ohmic and activation polarisations, after that the former overpotential became the main loss and the power density decreases to $0.05 \mathrm{~W} / \mathrm{cm}^{2}$ corresponding to $1.3 \mathrm{~A} / \mathrm{cm}^{2}$ as current density and $0.1 \mathrm{~V}$ as cell voltage. The concentration polarization remains small and then plays a minor role.

\subsection{Radiation effect on SOFC}

In this section, the numerical results of two geometric configurations, anode supported (AS) and electrolyte supported (ES) are presented since they are the most developed and used in the industry because of their better electric performances. First, the operating temperature influence is examined for two cases: heat source with and without radiation and then the current density influence is also investigated in order to have a better idea on the effect of radiation heat. 


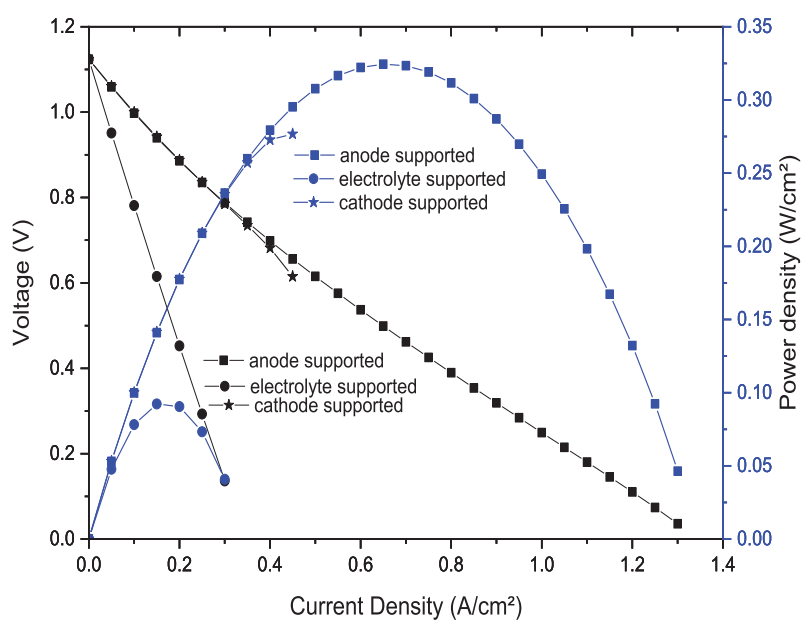

(a)

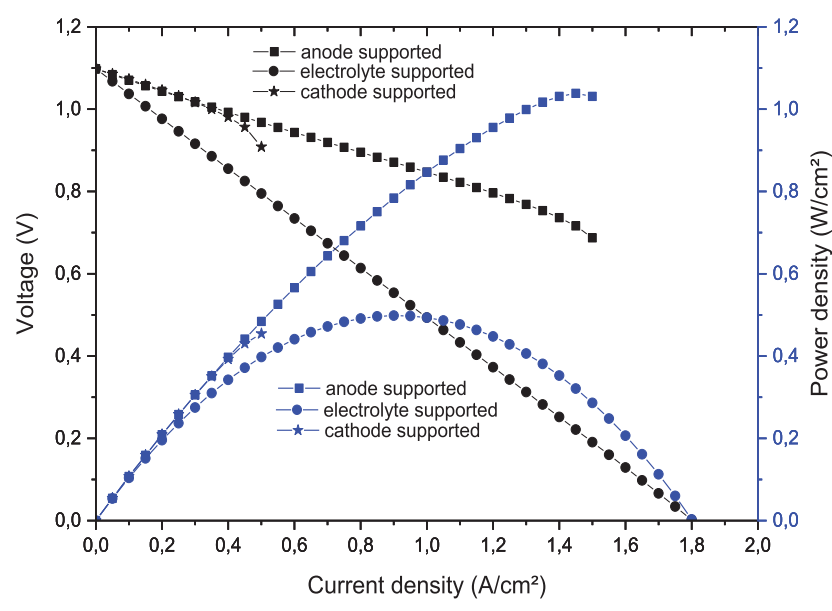

(c)

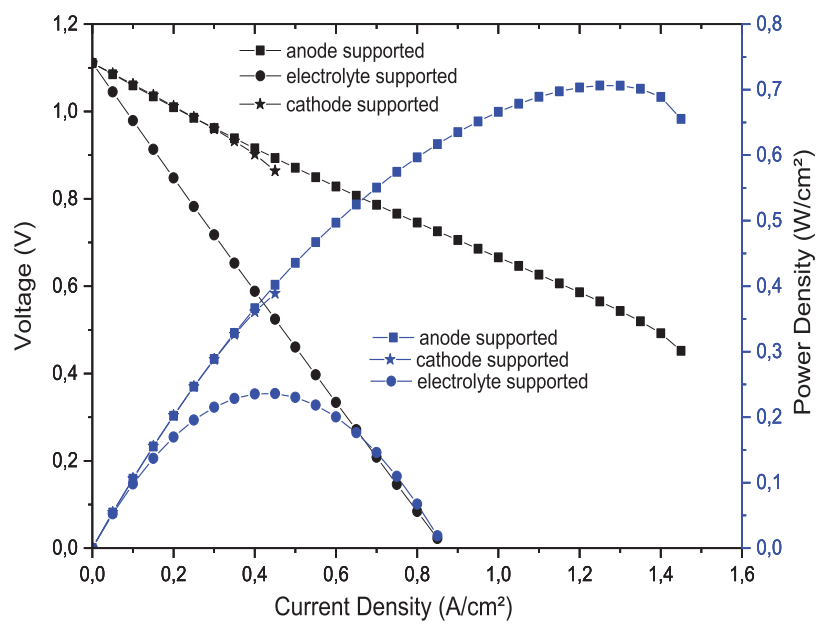

(b)

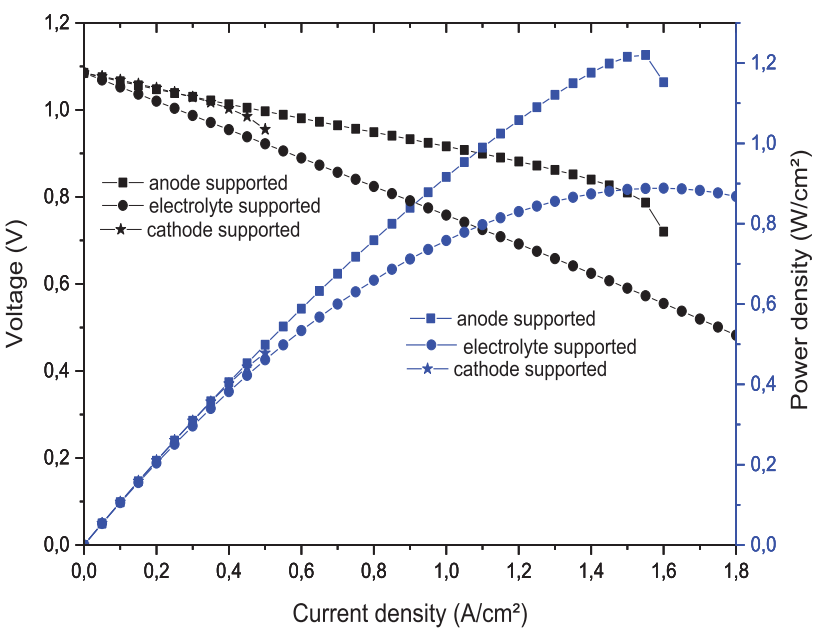

(d)

Fig. 4. Comparison of performance among anode, electrolyte and cathode supported SOFC. (a) T=1000 K, (b) $1100 \mathrm{~K}$, (c) $1200 \mathrm{~K}$ and (d) $1300 \mathrm{~K}$.

Table 2. Dimension of the planar cell.

\begin{tabular}{llll}
\hline Thickness $(\mu \mathrm{m})$ & Anode & Electrolyte & Cathode \\
\hline Anode supported & 300 & 50 & 100 \\
Electrolyte supported & 75 & 300 & 75 \\
Cathode supported & 100 & 50 & 300 \\
\hline
\end{tabular}

\subsubsection{Operating temperature influence on SOFC \\ 3.2.1.1 SOFC-AS}

The temperature field through the SOFC is shown in Figure 6 for various operating temperatures ranging from $1000 \mathrm{~K}$ to $1300 \mathrm{~K}$ with and without radiation heat. The shape of temperature distribution is the same for all cases. In fact, there is an increase of temperature in the entire cell

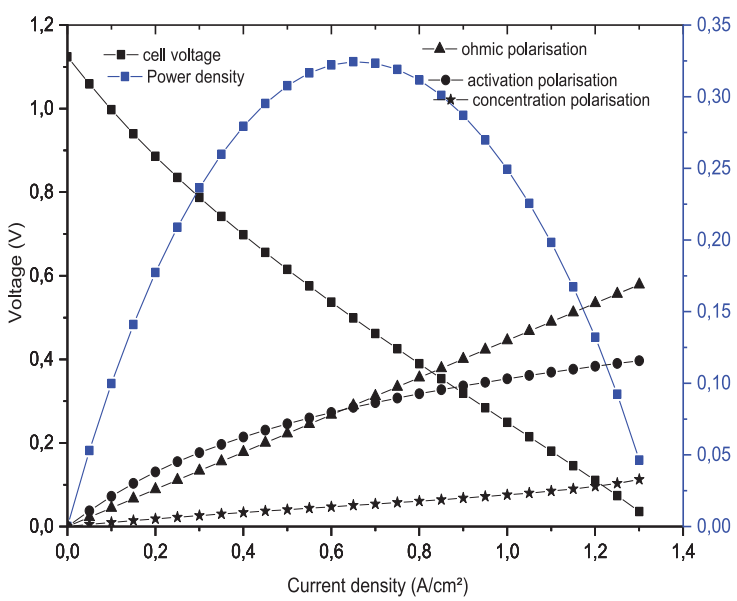

Fig. 5. Cell voltage, polarisation and power density versus current density at $1000 \mathrm{~K}$ for anode supported SOFC. 

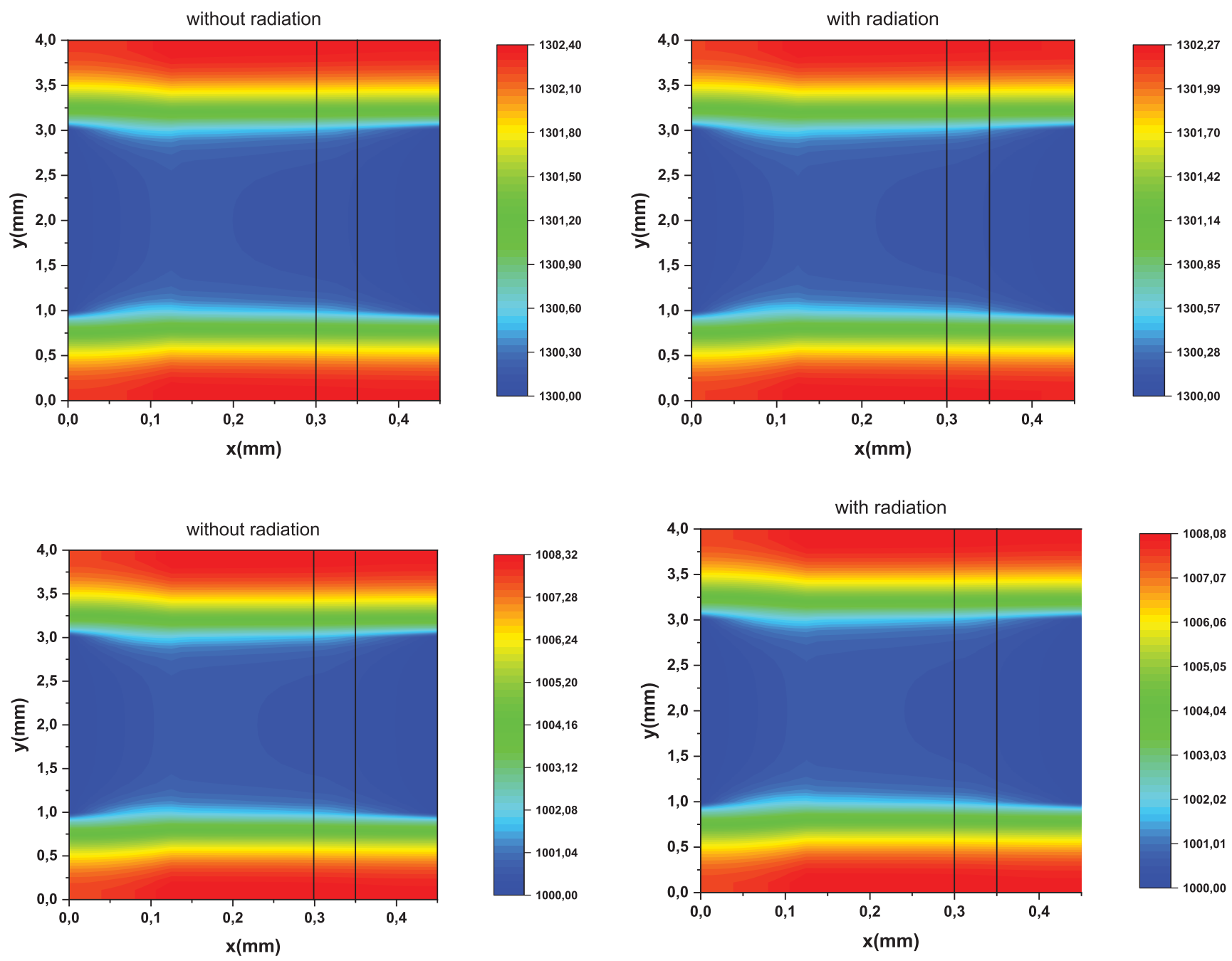

Fig. 6. SOFC-AS temperature field.

Table 3. Temperature effect.

\begin{tabular}{llllllll}
\hline$T(\mathrm{~K})$ & \multicolumn{2}{c}{ SOFC-AS } & & \multicolumn{2}{c}{ SOFC-ES } \\
\cline { 2 - 3 } & $\Delta T_{\text {(without radiation) }}$ & $\Delta T_{\text {(with radiation) }}$ & $\Delta T_{\max }$ & & $\Delta T_{\text {(without radiation) }}$ & $\Delta T_{\text {(with radiation) }}$ & $\Delta T_{\max }$ \\
\hline 1000 & 8.307 & 8.077 & 0.23 & & - & - & - \\
1100 & 4.167 & 4.017 & 0.15 & & 10.920 & 10.523 & 0.397 \\
1200 & 2.788 & 2.661 & 0.127 & & 5.666 & 5.406 & 0.26 \\
1300 & 2.396 & 2.260 & 0.136 & 3.677 & 3.468 & 0.206 \\
\hline
\end{tabular}

and hot temperatures are located in the electrolyte and near the interconnectors, due to the important heat dissipation by joule effect in the electrolyte and chemical reaction heat at the interface anode/electrolyte and especially the high heat resistance of the interconnector which constitutes a barrier to heat transfer and resulting in the accumulation of heat in these regions. As the operating temperature is increased, the difference between maximum and minimum temperature $\Delta \mathrm{T}$ decreases from 8.307 at $1000 \mathrm{~K}$ to 2.396 at $1300 \mathrm{~K}$ without radiation, and from 8.077 at $1000 \mathrm{~K}$ to 2.260 at $1300 \mathrm{~K}$ with radiation term, as illustrated in Table 3. This is because at higher temperatures the heat transfer by conduction becomes important and tends to make temperature field homogeneous in the entire SOFC. In addition, the radiation decreases the rise of temperature in the SOFC by enhancing heat transfer 

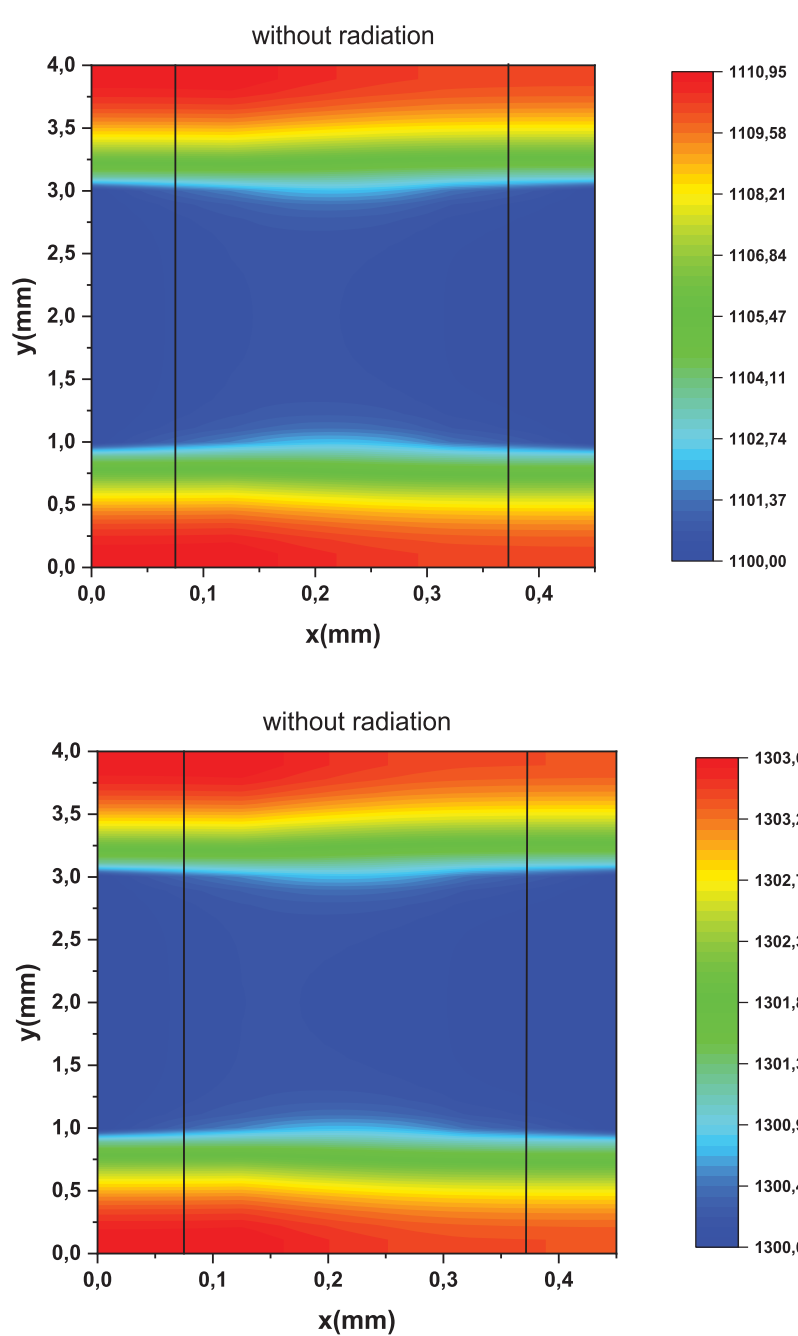
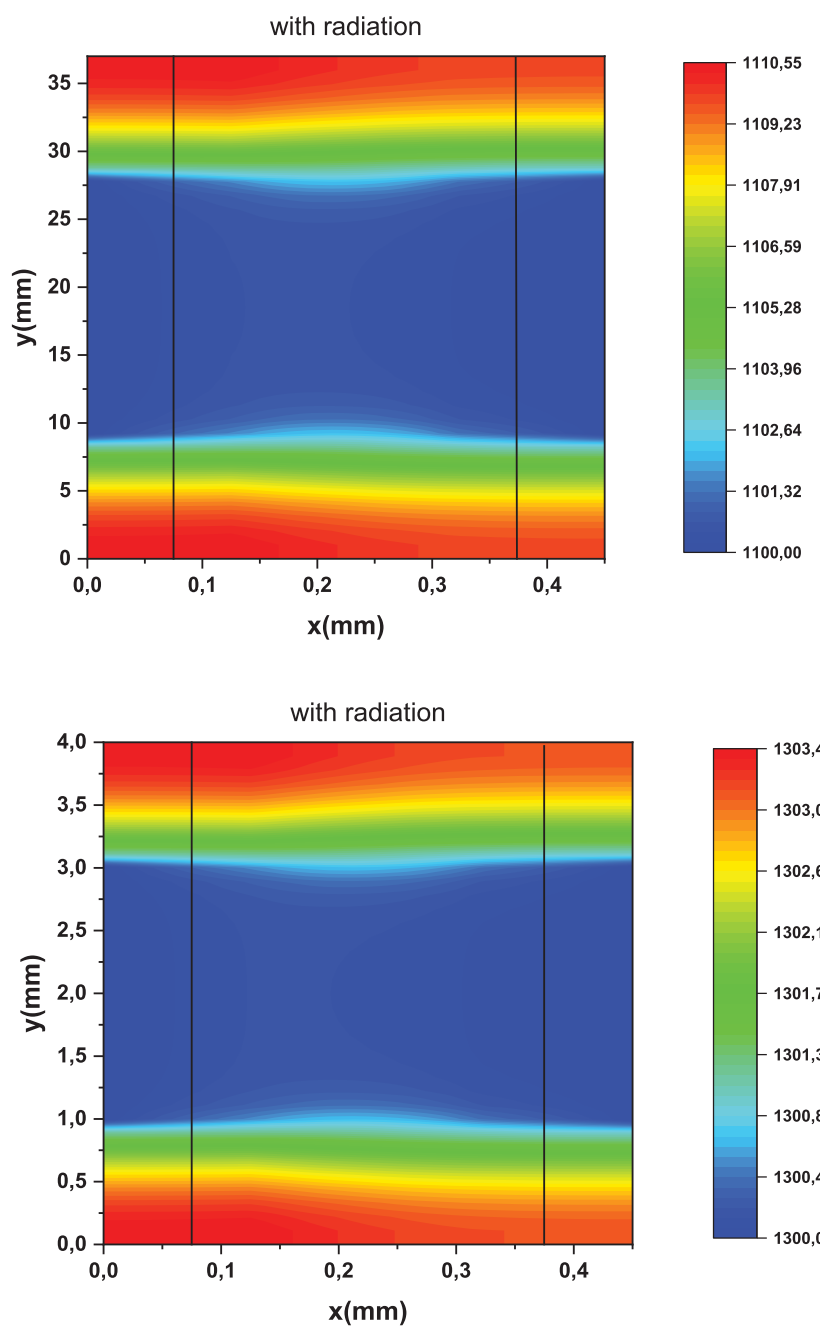

Fig. 7. SOFC-ES temperature field.

within it especially at intermediate temperatures and ceases to have an effect at higher temperatures as traduced by the difference $\Delta T_{\max }=\Delta T_{\text {without radiation }}$ $-\Delta T_{\text {with radiation. }}$

\subsubsection{SOFC-ES}

In case of supported electrolyte, the same observations seen in the previous case remained valid as shown in Figure 7. Except that the difference in temperature between maximum and minimum $\Delta T$ are much greater than in case of anode supported SOFC due to the higher ohmic overpotential in the thick electrolyte, from 10.920 at $1100 \mathrm{~K}$ to 3.677 at $1300 \mathrm{~K}$, without radiation and from 10.523 at $1100 \mathrm{~K}$ to 3.468 at $1300 \mathrm{~K}$ with radiation.

High temperatures are located near the interconnectors and the maximum is in the electrolyte zone. As the temperature increases, the electrical conductivity is improved resulting in weak ohmic overpotential and then the heat is mainly transported by conduction.
The radiation also enhances the heat diffusion, decreases temperature in the cell, and becomes negligible while temperature increases as illustrated by $\Delta T_{\max }$ in Table 3.

\subsubsection{Current density influence on SOFC \\ 3.2.2.1 SOFC-AS}

With increasing current densities, the temperature inside the cell increased since the different overpotentials and its relative heats depends on current density as shown in Figure. 8. For temperature equal to $1000 \mathrm{~K}$, the difference

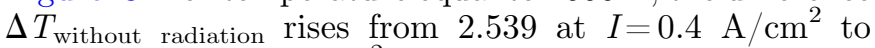
16.831 at $I=1.2 \mathrm{~A} / \mathrm{cm}^{2}$ and by varying the operating temperature to $1200 \mathrm{~K}$ and $1300 \mathrm{~K}$, it decreases each time by half as the electrical conductivity increases (Tab. 4).

When adding the radiation, the same thing is observed. By varying the current density, $\Delta T_{\text {with radiation }}$ increases from 2.470 at $I=0.4 \mathrm{~A} / \mathrm{cm}^{2}$ to 16.354 at $I=1.2$ $\mathrm{A} / \mathrm{cm}^{2}$ at temperature $1000 \mathrm{~K}$. For relatively high 

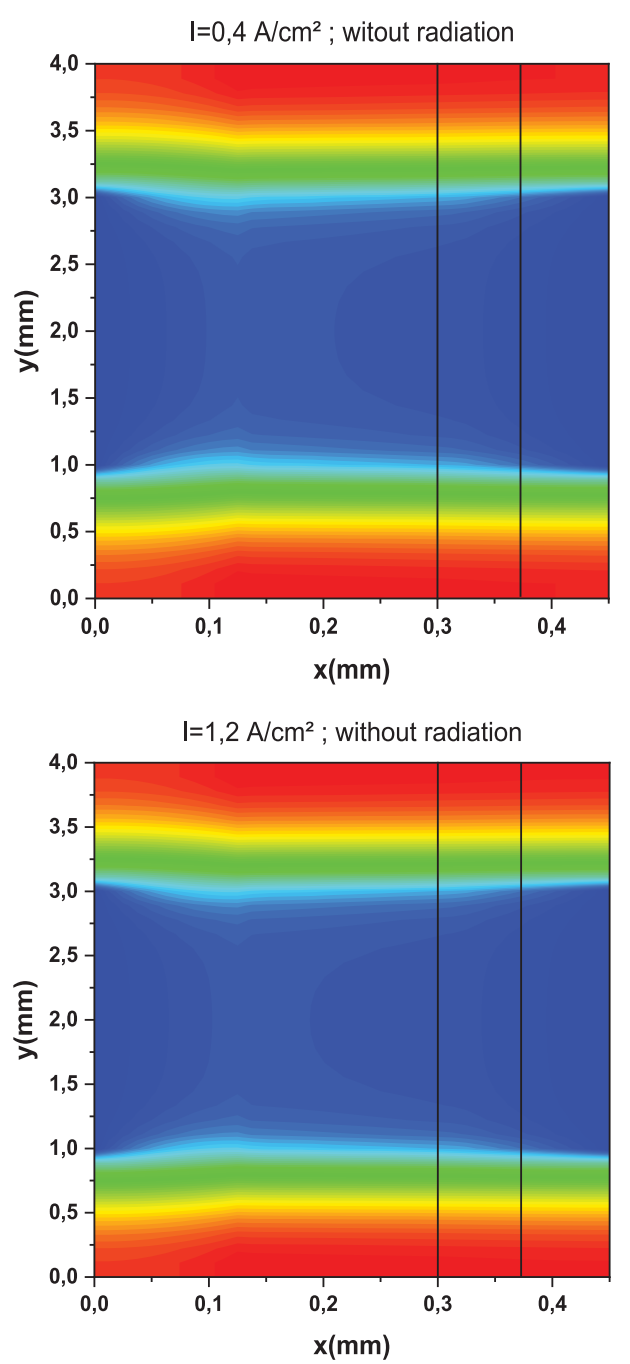
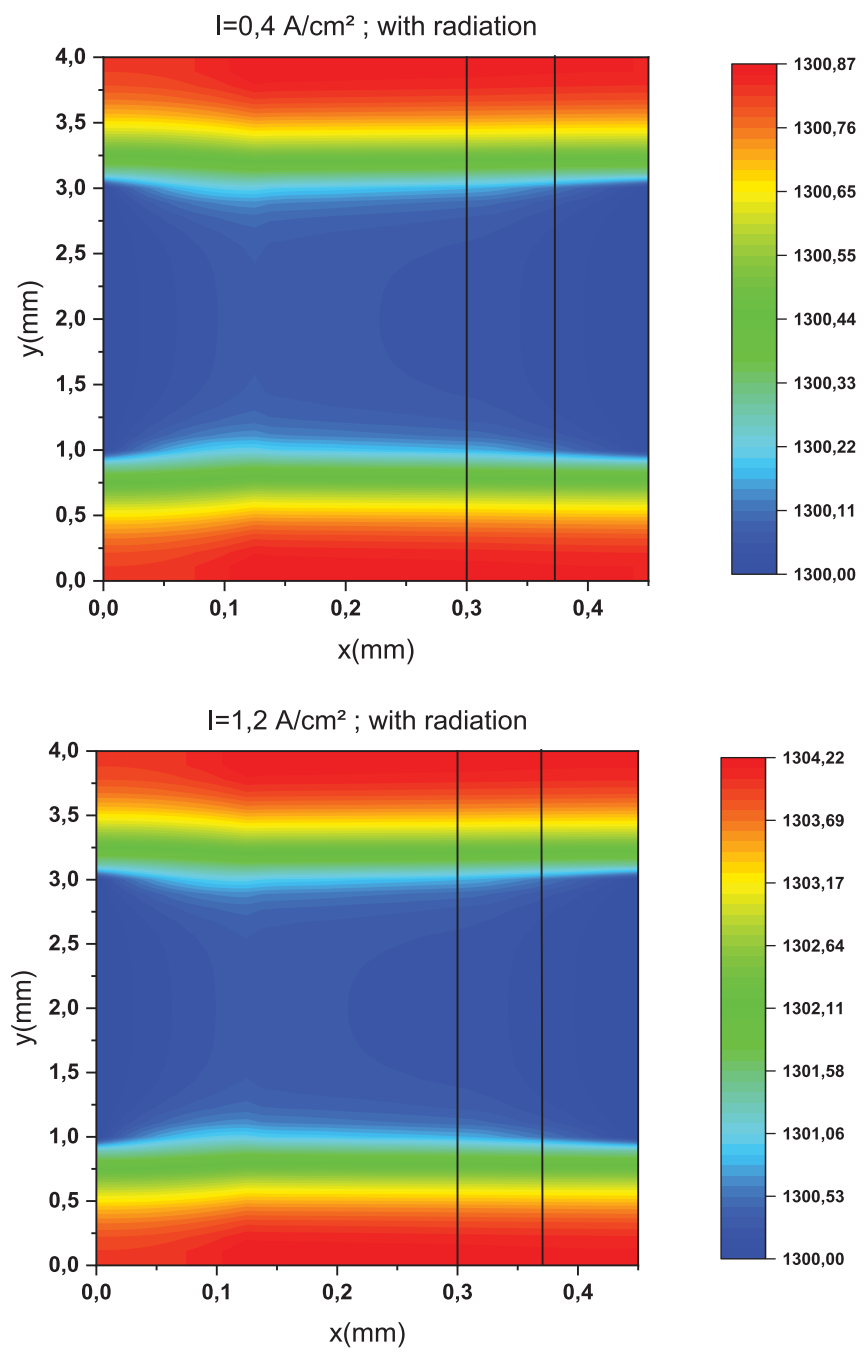

Fig. 8. Temperature field for anode supported SOFC under current density effect.

Table 4. Current effect on anode supported SOFC.

\begin{tabular}{lllll}
\hline & \multicolumn{3}{c}{ SOFC-AS } \\
\cline { 2 - 5 }$T(\mathrm{~K})$ & $I\left(\mathrm{~A} / \mathrm{cm}^{2}\right)$ & $\Delta T_{\text {(without radiation) }}$ & $\Delta T_{\text {(with radiation) }}$ & $\Delta T_{\max }$ \\
\hline 1000 & 0.4 & 2.539 & 2.470 & 0.069 \\
& 0.8 & 8.307 & 8.077 & 0.23 \\
1100 & 1.2 & 16.831 & 16.354 & 0.477 \\
& 0.4 & 1.320 & 1.273 & 0.047 \\
& 0.8 & 4.167 & 4.017 & 0.15 \\
1300 & 1.2 & 8.544 & 8.234 & 0.31 \\
& 0.4 & 0.922 & 0.871 & 0.051 \\
& 0.8 & 2.396 & 2.260 & 0.13 \\
& 1.2 & 4.464 & 4.208 & 0.256 \\
\hline
\end{tabular}

temperature equal to $1300 \mathrm{~K}$ the rise of temperature is decreased as the radiation improves the heat diffusion and then its effect is minimized. In Table $4, \Delta T_{\max }$ traduces the difference between the two cases, with and without radiation.

\subsubsection{SOFC-ES}

In the case of electrolyte supported, the temperature fields at $I=0.4 \mathrm{~A} / \mathrm{cm}^{2}$ and $I=1.2 \mathrm{~A} / \mathrm{cm}^{2}$ at $1300 \mathrm{~K}$ are illustrated in Figure 9, and the same phenomenon 

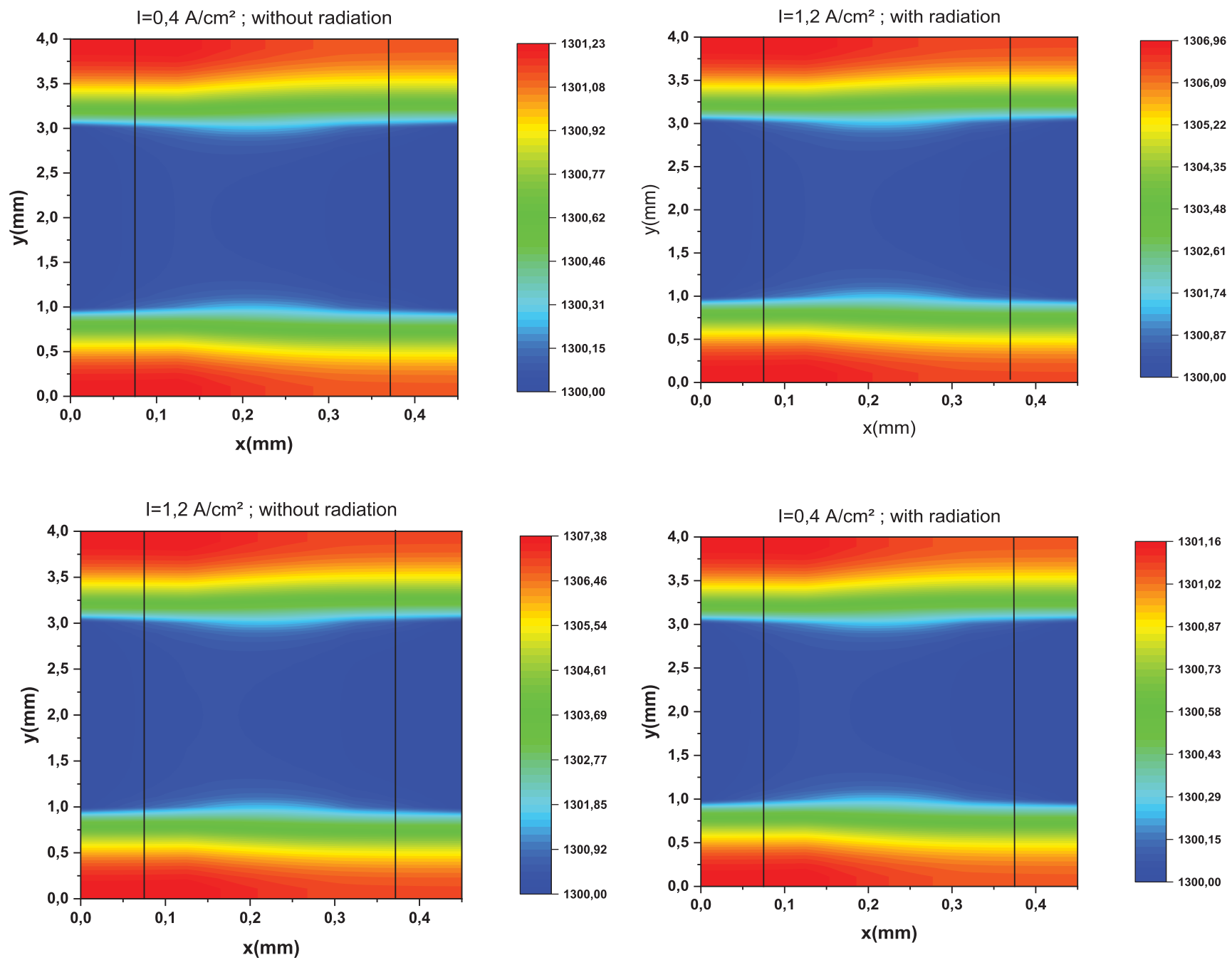

Fig. 9. Temperature field for electrolyte supported SOFC under current density effect.

Table 5. Current effect on electrolyte supported SOFC.

\begin{tabular}{lllll}
\hline \multicolumn{2}{c}{ SOFC-ES } & & \\
\hline $\mathrm{T}(\mathrm{K})$ & & $\Delta T_{\text {(without radiation) }}$ & $\Delta T_{\text {(with radiation) }}$ & $\Delta T_{\max }$ \\
\hline 1100 & 0.4 & 2.992 & 2.885 & 0.107 \\
& 0.8 & 10.920 & 10.523 & 0.397 \\
1200 & 1.2 & - & - & - \\
& 0.4 & 1.696 & 1.619 & 0.077 \\
& 0.8 & 5.666 & 5.406 & 0.26 \\
1300 & 1.2 & 11.932 & 11.377 & 0.555 \\
& 0.4 & 1.225 & 1.156 & 0.069 \\
& 0.8 & 3.677 & 3.468 & 0.209 \\
& 1.2 & 7.378 & 6.955 & 0.423 \\
\hline
\end{tabular}

are observed. However, the temperature rise within the SOFC is much greater than in case of anode supported geometry due to the joule heat losses in the thick electrolyte. Also the radiation affect globally the temperature distribution by decreasing the maximum temperature when current density is increased and become relatively negligible when operating at higher temperatures, as indicated by the differences $\Delta T_{\text {without radiation, }} \Delta T_{\text {with radiation }}$ and $\Delta T_{\max }$ in Table 5. 

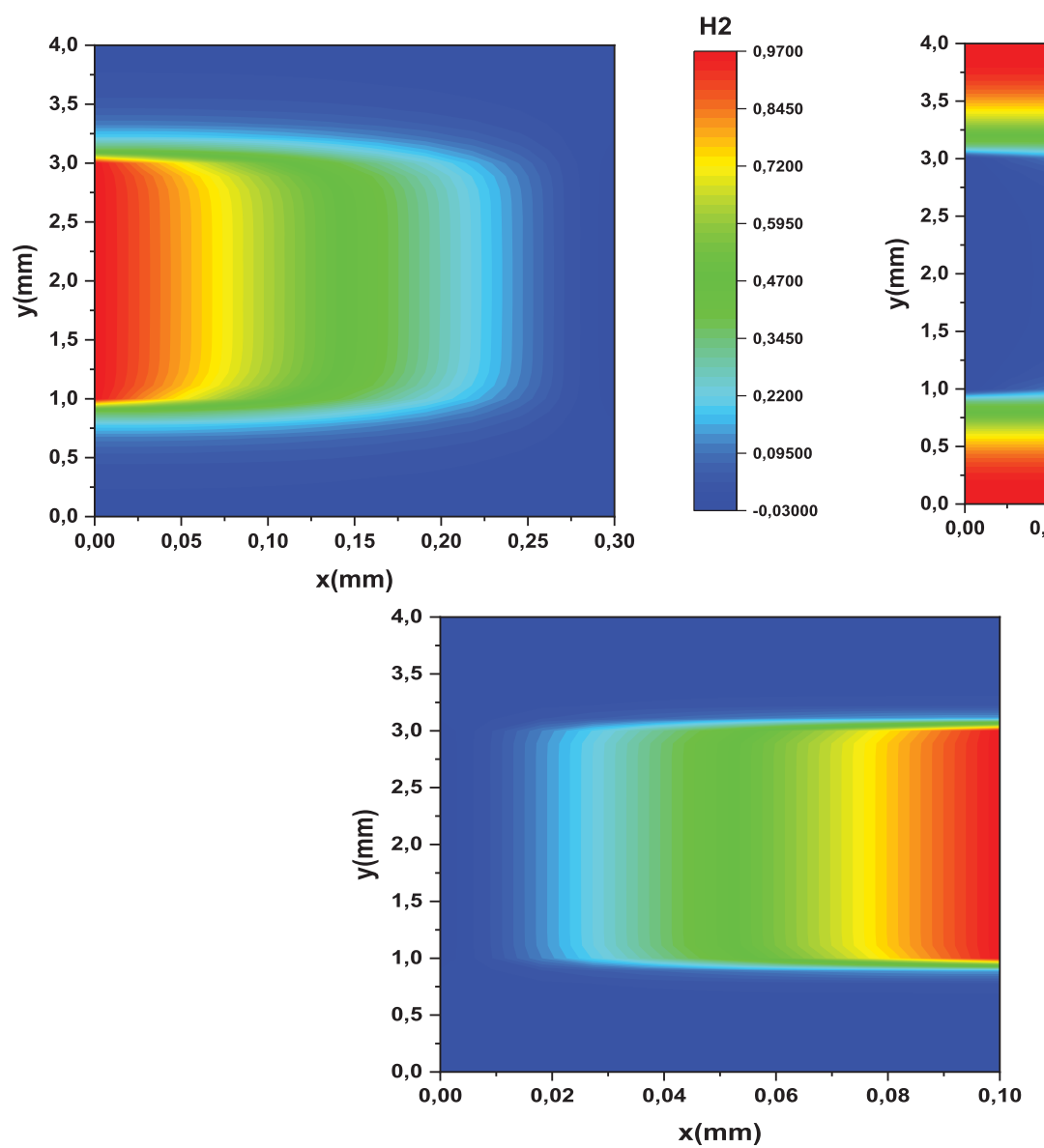

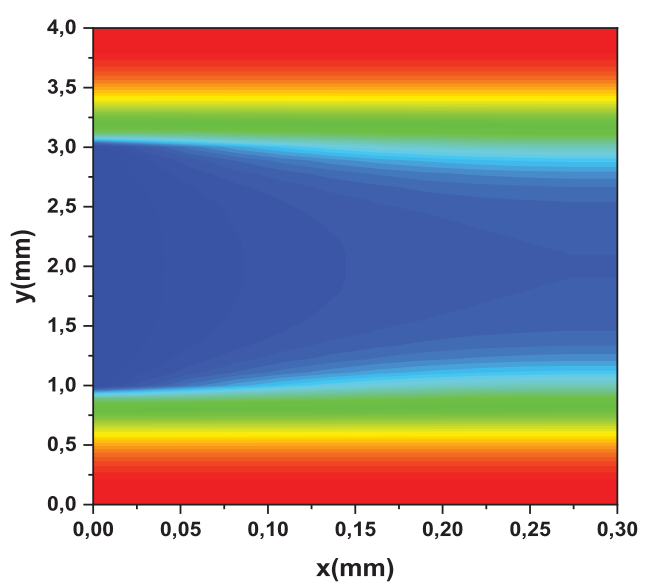

$\mathrm{H} 2 \mathrm{O}$

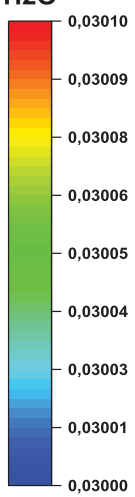

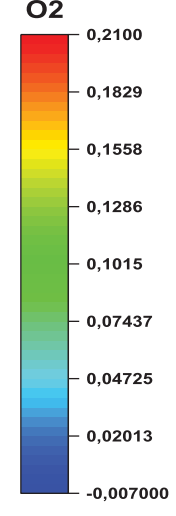

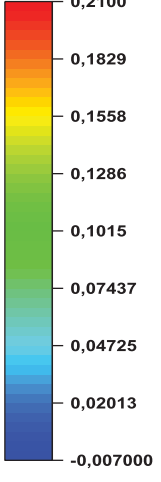

Fig. 10. Species mass fraction distribution; for an average current density $I=1.5 \mathrm{~A} / \mathrm{cm}^{2}$ and operating temperature $\mathrm{T}=1300 \mathrm{~K}$.

\section{Species distributions in the SOFC}

Figure 10 shows the different species mass distribution in the fuel cell, Hydrogen, water steam and Oxygen for anodesupported configuration. The results are carried out at operating temperature value of $1300 \mathrm{~K}$ and current density I equal to $1.5 \mathrm{~A} / \mathrm{cm}^{2}$. For the reactive $\mathrm{H}_{2}$ and $\mathrm{O}_{2}$, their mass fraction decrease in the direction of interface with the electrolyte where the reactions take place and maximal fractions are located near the channel flow interface. However, for water produced in gaseous phase in the interface anode/electrolyte, important fractions reach the interface and accumulated at the interconnectors where high values are reached.

\section{Conclusion}

The results obtained by the present numerical modelling lead to interesting conclusions. First, anode and electrolyte supported SOFCs show the best electric performances in terms of current and power densities especially at higher operating temperatures. Activation and ohmic polarisation are the main dominant voltage losses in the cell when the current increases and therefore it is reflected in power density and corresponding heat sources. Radiation plays a significant role on SOFC temperature distribution espe- cially in electrolyte semi-transparent media which allows heat transfer by radiation within it. In the contrary, electrodes supposed as an optically thick media have a minor effect. In fact, radiation improves the thermal diffusion inside the cell and counterbalance heat dissipation by ohmic and activation polarisations as well as reaction heat and the result is a decrease in temperatures especially in electrolyte. As the operating temperature increases, the effect of radiation becomes weak is and tend to homogenise the temperatures field. At higher current densities, the radiation influence becomes more significant within the cell, which allows concluding that when modelling thermal transport and heat management of SOFC, the radiation contribution should be taken into account especially when the cell operates at high current and intermediate temperature.

\section{Nomenclature}

$C_{p} \quad$ Specific heat at constant pressure $\left[\mathrm{J} \mathrm{kg}^{-1} \mathrm{~K}^{-1}\right]$

$D_{i} \quad$ Molecular diffusivity $\left[\mathrm{m}^{2} \mathrm{~s}^{-1}\right]$

$D_{\text {eff }} \quad$ Average effective diffusivity $\left[\mathrm{m}^{2} \mathrm{~s}^{-1}\right]$

$E_{0} \quad$ Open-circuit voltage at standard pressure [V]

$E_{\text {ideal }}$ Ideal potential [V]

$e^{\text {Gas internal energy }[\mathrm{J}]}$

$e_{k} \quad$ Thickness of each layer [ $\left.\mu \mathrm{m}\right]$

$F \quad$ Faradays constant $\left[96,485 \mathrm{~A} \mathrm{~s} \mathrm{~mol}^{-1}\right]$ 
$k \quad$ Absorption coefficient $\left[\mathrm{m}^{-1}\right]$

$k r \quad$ Radiative conductivity

$\Delta H \quad$ Enthalpy change of reaction, $\left[\mathrm{J} \mathrm{mol}^{-1}\right]$

$i \quad$ Current density $\left[\mathrm{A} \mathrm{m}^{-2}\right]$

$i_{0} \quad$ Exchange current density $\left[\mathrm{A} \mathrm{m}^{-2}\right]$

$n \quad$ Refractive index of the medium

$P \quad$ Pressure [bar or $\mathrm{Pa}$ ]

$P_{i} \quad$ Partial pressure [Pa]

$Q_{\text {chem }}$ Reaction heat $\left[\mathrm{W} \mathrm{m}^{-3}\right]$

$q_{\text {rad }} \quad$ Radiative heat flux $\left[\mathrm{W} \mathrm{m} \mathrm{m}^{-2}\right]$

$R \quad$ Gas constant $\left[8.3145 \mathrm{~J} \mathrm{~mol}^{-1} \mathrm{~K}^{-1}\right]$

$S \quad$ Heat source term $\left[\mathrm{W} \mathrm{m}^{-3}\right]$

$T \quad$ Temperature $[\mathrm{K}]$

$U \quad$ Velocity vector $\left[\mathrm{m} \mathrm{s}^{-1}\right]$

$\mathrm{V} \quad$ Cell voltage [V]

$\mathrm{X}$ Mass fraction

Greek symbols

$\beta_{r} \quad$ Extinction coefficient $\left[\mathrm{m}^{-1}\right]$

$\delta$ Layer thickness, where heat is produced $[\mu \mathrm{m}]$

$\varepsilon \quad$ Porosity

$\lambda$ Thermal conductivity $\left[\mathrm{W} \mathrm{m}^{-1} \mathrm{~K}^{-1}\right]$

$\gamma$ Pre exponential factor of the exchange current density, $\left[\mathrm{A} \mathrm{m}^{-2}\right]$

к Permeability $\left[\mathrm{m}^{2}\right]$

$\eta \quad$ Polarization [V]

$\mu$ Dynamic viscosity $[\mathrm{Pa} \mathrm{s}]$

$\rho \quad$ Density $\left[\mathrm{kg} / \mathrm{m}^{3}\right]$

$\sigma \quad$ Ion/electron conductivity $\left[\Omega^{-1} \mathrm{~m}^{-1}\right]$

$\tau$ Tortuosity factor

$\tau_{L}$ Total optical length of a medium

Abbreviations, subscripts and superscripts

$\begin{array}{ll}\text { an } & \text { Anode } \\ \text { act } & \text { Activation (polarization) } \\ \text { ca } & \text { Cathode } \\ \text { con } & \text { Concentration (polarization) } \\ \text { chem } & \text { Chemical (reaction) } \\ f & \text { Fluid } \\ I & \text { Interface electrode/electrolyte } \\ i & \text { Species index } \\ k & \text { Anode cathode or electrolyte } \\ \text { ele } & \text { Electrolyte material } \\ \text { ohm } & \text { Ohmic (polarization) } \\ s & \text { Electrode material } \\ \text { SOFC } & \text { Solid oxide fuel cell } \\ \text { SA } & \text { Supported anode } \\ \text { SE } & \text { Supported electrolyte } \\ & \end{array}$

\section{References}

[1] J. Hartvigsen, S. Elangovan, A. Khandkar, Modeling, design, and performance of solid oxide fuel cells, Proc. Sci. Technol. Zirconia 682-693 (1993)
[2] S. Murthy, A.G. Fedorov, Radiation Heat Transfer Analysis of the Monolith-Type Solid Oxide Fuel Cell, J. Power Sources 124, 453-458 (2003)

[3] D.L. Damm, A.G. Fedorov, Spectral radiative heat transfer analysis of the planar SOFC, J. Fuel Cell Sci. Technol, 2, 258-262 (2005)

[4] D.L. Damm, A.G. Fedorov, Radiation heat transfer in SOFC materials and components, J. Power Sources 143, 158-165 (2005)

[5] K.J. Daun, S.B. Beale, F. Liu, Radiation heat transfer in planar SOFC electrolytes, J. Power Sources 157, 302-310 (2006)

[6] B. Grzegorz, J.S. Szmyd. Numerical modelling of radiative heat transfer in an internal indirect reforming-type SOFC, J. Power Sources 181, 8-16 (2008)

[7] R.J. Kee, B.L. Kee, J.L. Martin, Radiative and convective heat transport within tubular solid-oxide fuel-cell stacks, J. Power Sources 195, 6688-6698 (2010)

[8] C. Bao, N. Cai, E. Croiset, An analytical model of view factors for radiation heat transfer in planar and tubular solid oxide fuel cells, J. Power Sources 196, 3223-3232 (2011)

[9] I. Mejri, A. Mahmoudi, M.A. Abbassi, A. Omri, Radiation Heat Transfer Effect in Solid Oxide Fuel Cell: Application of the Lattice Boltzmann Method, International Journal of Mathematical, Computational, Physical, Electrical Comp. Eng. 8 (2014)

[10] M. Garcia-Camprubi, H. Jasak, N. Fueyo, "CFD analysis of cooling effects in H2-fed solid oxide fuel cells" J. Power Sources 196, 7290-7301 (2011)

[11] D. Ferrero, A. Lanzini, M. Santarelli, Solid Oxide Fuel Cells Modeling, Advances in medium and high temperature solid oxid fuel cell technology, CISM Int. Centre Mech. Sci. 574, 291-342 (2017)

[12] I. Tikiz, Huseyin Pehlivan, CFD modelling and experimental validation of cell performance in a $3-D$ planar SOFC, Int. J. Hydrogen 44, 15441-15455 (2019)

[13] L. van Biert, M. Godjevaca, K. Visser, P.V. Aravind, Dynamic modelling of a direct internal reforming solid oxide fuel cell stackbased on single cell experiments, Appl. Energy 250, 976-990 (2019)

[14] S. Yixiang, C. Ningsheng, L. Chen, Numerical modelling of an anode-supported SOFC button cell considering anodic surface diffusion, J Power Sources 164, 639-48 (2007)

[15] M. Ni, M.K.H. Leung, D.Y.C. Leung, Parametric study of solid oxide fuel cell performance, Energy Convers. Manag. 48, 1525-1535 (2007)

[16] P. Aguiara, C.S. Adjiman, N.P. Brandon, Anode-supported intermediate temperature direct internal reforming solid oxide fuel cell. I: model-based steady-state performance, J. Power Sources 138, 120-136 (2004)

[17] M. Chnani, Modelisation Macroscopique de piles PEFC et SOFC pour l'étude de leur couplage, Thèse de doctorat. Institut FEMTO-ST- Département ENISYS UMR CNRS 6174-UFC - ENSMM - UTBM. (2008)

[18] F. Zhao, A.V. Virkar, Dependence of polarization in anodesupported solid oxide fuel cells on various cell parameters, J. Power Sources 141, 79-95 (2005)

[19] CFD Fluent 6.2.16

Cite this article as: W. Alimi, R. Chouikh, A.A. Guizani, SOFC modelling considering radiation heat transfer, Mechanics \& Industry 21, $306(2020)$ 